\title{
Melville y Grau: NAVEGACIONES PARALELAS
}

\author{
Melville and Grau: parallel navigations
}

Aldo Vivar Mendoza ${ }^{1}$

\begin{abstract}
Resumen
El presente texto repasa las experiencias marinas de dos eminentes personajes: Herman Melville, escritor norteamericano, y Miguel Grau, marino peruano. En ellos, el Océano Pacífico dejó huellas indelebles en sus vidas y en sus obras.
\end{abstract}

Palabras claves: Herman Melville, Miguel Grau, Moby Dick.

Abstract

This paper reviewed the marine experiences of two eminent figures: Herman Melville, American writer, and Miguel Grau, Navy Peruvian. In them, the Pacific Ocean left indelible traces in their lives and in their work.

Keywords: Herman Melville, Miguel Grau, Moby Dick.

erman Melville no hubiese podido escribir Moby Dick sin su experiencia en un barco ballenero así como Miguel Grau no hubiese desarrollado las proezas navales durante la guerra sin el amplio conocimiento del mar que adquirió siendo niño. Ambas personalidades particulares tuvieron vidas paralelas, aunque en realidad lo que compartieron fueron navegaciones comunes en las mismas aguas, que en aquel entonces era llamado el Mar del Sur. Melville tenía veintidós años cuando asomó por primera vez por el puerto de Paita en 1842, Grau tenía ocho años y ya vivía allí pues su padre fue nombrado inspector de la aduana. En el lapso de unos pocos meses ambos estarían navegando el mismo mar.
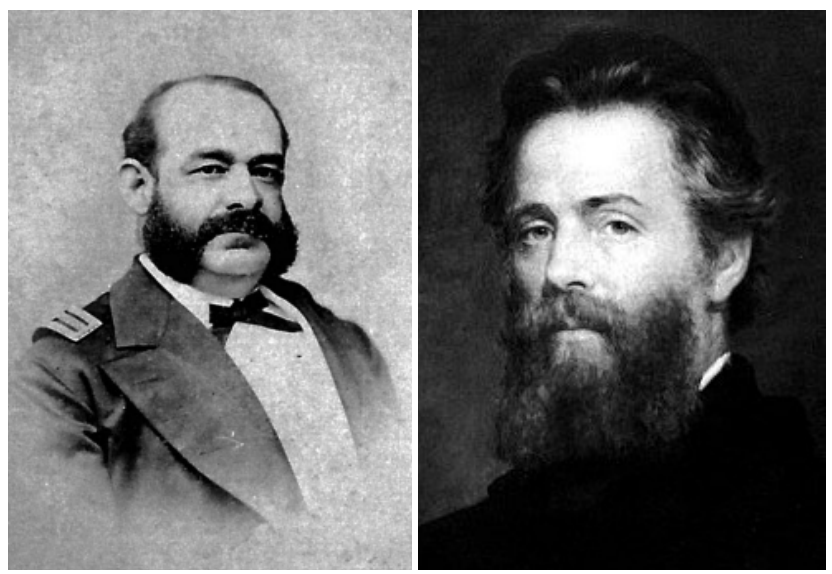

El Mar del Sur obtuvo ese nombre por la particular posición de Panamá -sobre todo el istmo de Darién- respecto al océano, sus playas miran al norte y al sur a diferencia de los sudamericanos que miran el mar al oeste o al este. En 1512 Vasco Núñez de Balboa estaba al mando de la guarnición de Darién cuando tuvo noticias de un mar extenso y decidió iniciar una expedición, que fue a la vez audaz y llena de penalidades. Balboa llegó a las faldas de un cerro desde cuya cima podía ver el mar, ascendió solo y al llegar a la cumbre cayó de rodillas al contemplar aquella inmensidad. A la mañana siguiente, ya en armadura se adentró en sus aguas y con medio cuerpo sumergido lo anexó al dominio del rey de Castilla y León

\footnotetext{
Médico internista. Hospital Nacional Arzobispo Loayza. Universidad Peruana Cayetano Heredia.
} 
con el nombre de Mar del Sur. ${ }^{(1)}$ Su nuevo y actual nombre lo recibió de Magallanes quien al atravesar las enormes peripecias por el oscuro y peligroso estrecho que ahora lleva su nombre encontró un mar sereno y tranquilo, al contemplarlo, Magallanes henchido de emoción soltó lágrimas, al abrirse el ancho océano, el Mar del Sur, contemplado ahora desde la zona más austral del planeta y luego de sobrevivir al viaje lo bautizó como Pacífico, pues en ese momento aquel mar mostró su mejor cara. ${ }^{(2)}$

Este océano ha albergado viajes inmemoriales, los antiguos nativos en sus pequeñas barcas, los viajes de Tupac Yupanqui hacia Oceanía, expediciones como las de Magallanes -que descubrió su inmensidad- o la de James Cook, quien en sus tres viajes fue testigo de su peligrosidad así como de la riqueza de su fauna. Luego de la Conquista el Imperio Español lo haría su territorio excluyente - de acuerdo a la división del mundo reglamentada por el Tratado de Tordesillas-. Sin embargo, este océano fue invadido por esporádicas incursiones pesqueras o de contrabando así como asaltado de cuando en cuando por piratas ingleses y holandeses. La respuesta española fue el refuerzo de las actividades marítimas de la Armada así como el desplazamiento de expediciones científicas que tuvieran el mar bien vigilado pero esto no fue suficiente.

En 1774 el capitán de la fragata de guerra Santiago, don Juan Pérez, descubrió una ensenada al norte de California que era ideal para el atraque de barcos y así poder realizar el comercio de pieles de nutria con los nativos, la ensenada recibió el nombre de San Lorenzo de Nootka, cuatro años más tarde el capitán

\footnotetext{
Melville, Herman. Los Mares del Sur. En: Viajar, pp: 28-30. Gadir Editorial. Madrid. 2011.

2 Op. cit. pp: 30-31
}

Cook rebautizó el lugar como Friendly Cove debido a lo amistoso del comercio con los nativos. Desde entonces el lugar se convirtió en parada obligatoria de barcos de diversas nacionalidades para traficar con pieles. ${ }^{(3)}$ En 1789 ocurrió un confuso incidente, una expedición española alertó sobre la presencia de tres barcos extranjeros, un estadounidense, un portugués y un británico en Friendly Cove. El Conde de Revillagijedo, virrey de México, quiso reivindicar ese territorio para España y dispuso el apresamiento de aquellos barcos, luego liberó a dos pero retuvo al británico. Este hecho creó un conflicto diplomático ya que la respuesta británica fue furibunda amenazando con la guerra si no se restituían los perjuicios por el incidente de Nootka y se otorgaba la libre navegación para Inglaterra un privilegio que los insulares buscaban desde años atrás-. Por entonces España económica y geopolíticamente tenía un poder disminuido así no le quedó más que negociar y firmar con el reino de Inglaterra el Tratado de San Lorenzo en el Escorial el 28 de octubre de 1790, merced a ello se permitía la libre navegación de las naves británicas en el Mar del Sur. ${ }^{(4)}$ Con esto se había quebrado el monopolio español y la libre navegación tendría efectos de todo tipo desde los comerciales hasta los políticos que terminarían alentando los deseos de independencia de las colonias. Los ingleses gozaron del privilegio de la libre navegación así como del desembarco y apresto de sus naves, en compensación debían impedir el contrabando. ${ }^{(5)}$ La historia nos demostró que

\footnotetext{
3 Vicuña Mackenna, Benjamín. Historia de Valparaíso Tomo II. Capítulo LIII La pesca de la ballena en las costas de Chile. pp: 379

4 Pereira Salas E. Los primeros contactos entre Chile y los Estados Unidos 1778-1809. Editorial Andrés Bello. 1971. Cap III La apertura del Pacífico a los balleneros, pp 33.

5 Flores Guzmán R. Los balleneros anglo estadounidenses y la cuestión de la "extranjerización" del comercio peruano a fines de la época colonial . América latina en la Historia Económica. 2011; 36: 39-63
} 
las normas nunca se cumplieron a cabalidad.

En aquella época la caza de ballenas era una importante actividad económica que se realizada solo en el océano Atlántico debido al bloqueo español. Desdeel siglo IXel serhumano se había percatado del enorme potencial de la explotación de productos derivados de ballenas, aquellas que quedaban varadas en la playa o las que se acercaban muy cerca de la orilla, sobre todo en los mares del hemisferio norte. Se considera que fueron los vascos los primeros en adoptar la caza de ballenas como una actividad económica, los registros datan de 1150 cuando el rey Sancho el Sabio en San Sebastián concedió privilegios para este tipo de caza. ${ }^{(6)} \mathrm{A}$ ambos lados del Atlántico, vascos y esquimales adquirieron destreza, experiencia que fue aprovechada por los británicos y luego por los estadounidenses en las costas de Nueva Inglaterra. El procedimiento de aquellas primeras cazas ocurría a orillas del mar cuando un vigía divisaba una ballena y rápidamente salían del puerto pequeñas barcas para dar caza al animal. Con el tiempo las ballenas, como mecanismo de defensa, se alejaron de las costas. Entonces la caza migró a alta mar.

El acicate para las labores de caza era muy alto debido al enorme rendimiento económico. Paralelamente al valor de los productos de la ballena, los barcos se dedicaron también a la caza de lobos marinos por el alto costo de venta de sus pieles, sobre todo en Oriente. Un valor agregado en estos barcos lo constituían las mercancías suntuarias que eran comercializadas en los puertos. Los primeros armadores fueron los británicos pero rápidamente la actividad comercial derivó a los puertos de Nueva Inglaterra, actividad que

6 Spears J. The Story of New England Whalers. Mac Millan Company. New York, 1920, pp:20 comenzó casi inmediatamente después de la llegada de los primeros colonos a Cape Cod en el Mayflower quienes divisaron a las ballenas muy cerca de su embarcación, notando tiempo después los nativos de la zona -los pieles rojas- aprovechaban de las ballenas varadas en la playa. ${ }^{(7)}$

Elproductodeballenamás preciadoera elaceite, obtenido luego de hervir trozos de la carne de animal, con el que se hacían velas y servía como combustible para la iluminación pública, además en el caso de los cachalotes (sperm whales o Physeter macrocephalus) se obtenían otros productos: el espermaceti (sustancia alojada en una cavidad cefálica) -grasa que a temperatura corporal es líquida y al enfriarse se solidifica -por lo que erróneamente se confundió con el esperma reproductivo-, el espermaceti era usado en la producción de perfumes, velas y como lubricante en la industria textil; el ámbar gris, una sustancia grasosa que se forma en el intestino del cachalote para proteger su mucosa del daño de algunos alimentos como son los huesos de las presas ingeridas, esta grasa también era utilizada en la producción de perfumes. Asimismo, los llamados dientes de la ballena (o barbas), placas de queratina que penden de la parte superior de la boca y que funcionan como filtro para atrapar el krill, eran utilizados para dar armazón a los corsés o como accesorios para la ropa.

Las embarcaciones estadounidenses procedentes de los puertos de Nueva Inglaterra se hicieron a la mar para comerciar y cazar ballenas en las aguas del Pacífico, inicialmente lo hacían camufladas bajo bandera británica pues no gozaban del permiso español. En 1789 salió el primer buque ballenero -el Beaver- desde Nantucket (Massachusetts) en

$7 \quad$ Spears, Op cit, pp 2 
cruzar el cabo de Hornos hacia el Pacífico, luego de cumplir su misión acoderó en el Callao para aprovisionarse antes de regresar a Nueva Inglaterra y no fue bien recibida por los aduaneros españoles ${ }^{(8)}$. Luego lo haría el Washington -el primero con bandera estadounidense- y más tarde el Rubi y Favorita, siendo avistados en 1794 en los puertos de Pisco y Coquimbo. Ante el mayor número de barcos balleneros, de cazadores de pieles y comerciantes sin autorización para navegar los Virreyes de Lima - primero Gil de Taboada y luego Ambrosio O’Higgins- dispusieron su apresamiento $\mathrm{y}$, ante la solicitud de los comerciantes criollos, armaron corsarios para combatir la incursión ilegal de naves. Tales medidas fueron insuficientes. Merced a negociaciones diplomáticas, finalmente el 27 de octubre de 1795 se firmó el Tratado de Paz en San Lorenzo entre el Plenipotenciario del Rey Carlos III de España -Manuel de Gody, Príncipe de la Paz- y Thomas Pinckney -en representación del presidente de los Estados Unidos- gracias a este tratado los barcos estadounidenses obtuvieron la legalidad para sus actividades de caza y comercio. La industria ballenera tuvo carta libre y dinamizó la actividad comercial del litoral oeste de América del Sur, un tanto abandonado pues la Armada española y los barcos mercantes del Imperio estaban entretenidos en los conflictos con Francia.

En aquellos tiempos se vivía una turbulencia política en Europa, de manera sorpresiva España entró en guerra con Inglaterra, esto motivó un mayor ingreso de barcos estadounidenses pues los británicos eran perseguidos y obligados a pescar mar adentro o camuflarse con la bandera estadounidense. En el Perú sus puertos favoritos eran el Callao

8 Johnson J. Early relations of the United States with Chile. Pacific Historical Review. 1944;13(3):260-270. y Paita, es en este último sitio donde confluyen nuestros personajes singulares, hombres jóvenes -como era la costumbre de la épocaque se hacen a la mar en busca de ballenas.

Uno de ellos fue Herman Melville (Nueva York, 1ro de agosto de 1819), su padre, Allan, fue un comerciante importador y su madre, Maria Gasenvoort, una dama perteneciente a una familia holandesa de abolengo y de una rígida tradición calvinista. Sus dos abuelos fueron héroes de la Revolución por la Independencia de los Estados Unidos, Thomas Melvill fue miembro del Boston Tea Party y amigo de Paul Revere, Peter Gasenvoort fue un militar que luchó contra los británicos. Herman fue el tercero de ocho hermanos que nacieron con asombrosa regularidad cada dos años entre 1815 y 1830. A pesar de sus antecedentes sociales los Melvill (la e se agregó luego) nunca lograron una buena situación económica, Allan Melvill, el padre, fracasó en los negocios pues era aficionado al crédito y a los juegos de azar, dilapidó su herencia y cayó en la bancarrota falleciendo un invierno de una enfermedad febril y delirante -una neumoníacuando Herman tenía 12 años -momento en que Maria Gasenvoort añade la $e$ al apellido Melville- . La situación familiar se tornó crítica por lo que Herman comenzó a trabajar en un banco de Albany como mensajero, mudándose allí con su hermano mayor. Luego, con estudios suficientes en los años previos logra ejercer como maestro de escuela en 1837. Poco tiempo después los hermanos se mudaron nuevamente a Nueva York y al cabo de unos meses Herman, en busca de una mejora salarial, se embarcó como tripulante en el St. Laurence hacia Liverpool (Inglaterra) en 1839, un viaje que duró cuatro meses, la nave trasnsportaba algodón con destino a las textilerías británicas. Como marinero aprendería la rigidez y disciplina de la vida en alta mar, viaje que por otro lado sería un escape a sus angustias 
financieras. A su retorno Herman volvería a sus actividades como maestro. Esta primera experiencia naviera inspiró su novela Redburn (1849) obra que dedicó a su hermano Thomas. Sin embargo la docencia duraría poco y el joven Herman pronto se embarcaría en una nueva aventura marítima. Para entonces la presencia de balleneros estadounidenses en los Mares del Sur era muy activa, consecuencia de una actividad iniciada a finales del siglo XVIII y potenciada con la independencia de las colonias españolas. Casi la totalidad de barcos balleneros zarpaban entonces de los puertos de Fairhaven, New Bedford, Edgartown y Nantucket en Nueva Inglaterra, es por ese motivo que los barcos tienen un nombre que indica además el puerto de origen, Herman, con 22 años, con sed de aventura y libertad, para escapar de sus problemas y atraído además por la presencia de una biblioteca dentro de la nave se embarca en el ballenero Acushnet de Fairhaven, zarpando el 3 de enero de 1841, una nave propiedad de Bradford, Fuller and Co, bajo las órdenes del severo capitán Valentine Pease. ${ }^{(9)}$ El Acushnet tiene un tonelaje de 359 toneladas con destino al Pacífico Sur cuya ruta incluyó las islas Azores, las costas del Brasil, luego al Cabo de Hornos desde donde enrumba hacia las costas del Perú. A partir de sus obras sabemos que estuvo en Lima y Paita, cuyas notas sobre estos poblados aparecerían varios años después en Las Encantadas, White Jacket, Oomo, Benito Cereno y Moby Dick.

Desde Paita, bahía con especiales condiciones portuarias enrumbaría hacia las Islas Galápagos y luego de una estadía corta viajaría hasta las islas Marquesas donde desertará con un compañero para vivir en una pequeña isla junto a los nativos y aprenderá sus costumbres

9 Starbuck A. History of the American Whale Fishery, from its early inception to the year 1876. Agnosty Antiquarian Ltd. New York 1964 pp 376-7. pero asustado ante la eventualidad de canibalismo decidió escapar para ser rescatado por un ballenero australiano, el Lucy Ann, que luego sufrió un motín debido a la crueldad del capitán y la pobreza de la pesca. Herman y un amigo terminaron encarcelados en Papetee. Fueron liberados una vez que el Lucy Ann salió del puerto. Herman se embarcó en el ballenero Charles $\mathcal{E}$ Henry de Nantucket. Cuando llegan a Honolulu, Hawaii, decidió quedarse unos meses consiguiendo trabajo como asistente contable y vendedor en una casa importadora. Al poco tiempo se desencanta del lugar debido a la brutal explotación de os nativos por lo que decide embarcarse en el United States, una fragata naval, que retorna a Boston en 1844.

A partir de su experiencia marítima, Herman decide relatarla en novelas como Typee (1846) y Omoo (1847) que se convierten en éxitos literarios -en 1847 también contrae matrimonio con Lizzie Shaw, hija de un juez Supremo de la Corte de Massachusetts que fue amigo de su padre- luego publica Mardi y Redburn (1849), White Jacket (1850) con resultados dispares. Estas obras contienen su opinión sobre la vida y la sociedad, la claridad de los detalles de la aventura marítima hace pensar que fueron escritas "a bordo". Por otro lado el matrimonio Melville tiene su primer hijo, Malcolm, en 1849. Seguirían Stanwix (1851), Elizabeth (1853) y Frances (1855).

Una vez en tierra y asentado en el matrimonio Herman Melville no vuelve a embarcarse en balleneros ni ninguna otra nave mercante, se asienta en tierra para tomar otro tipo de viaje, el literario. Melville no tuvo una educación formal pero se inició con la lectura de los clásicos como Dante, Rabelais, Montaigne y Shakespeare para afinar su capacidad literaria. Melville vivió en Nueva York de 1847 a 1850 pero agobiado por la intranquilidad que era vivir en una casa habitada además por 
su madre y al familia de su hermano Allan decidió mudarse a una finca de 160 acres en las montañas Berkshire en Massachusetts a la que llamó Arrowhead. En la finca vecina encuentra que su vecino es Nathaniel Hawthorne, el renombrado escritor de Boston, quince años mayor, quien induce una transformación en su manera de pensar y con quien inicia un intercambio epistolar, este hecho y su inclusión en círculos literarios donde participaba también Oliver Wendell Holmes le sirvieron de base para dedicarse a escribir durante un año su obra fundamental, Moby Dick, la fábula de la búsqueda despiadada del capitán Pequod persiguiendo obsesivamente una ballena blanca responsable de haberle cercenado una pierna. Moby Dick es una obra maestra pero que tuvo una pobre acogida, la novela mezcla reflexión metafísica, ensayo científico y relato que revelan las múltiples dimensiones de la naturaleza humana. Una novela del siglo XX escrita en el XIX.

La lectura de Moby Dick es como ver un prisma con sus múltiples resplandores. No solo es el relato de aventuras de un barco ballenero sino también fuente de datos en ciencias, geografía, literatura, antropología, filosofía, historia y religión. El siglo XIX aparece a través de esta novela, como la consolidación del racionalismo científico, el coraje humano, lo inconmensurable de la divinidad y la supremacía del comercio marítimo.

Moby Dick fue un fracaso literario. Sus siguientes obras Pierre (1852), Israel Potter (1855), Piazza Tales (1856) -que incluye Benito Cereno, Las Encantadas, Bartleby, The Piazza y The Bell Tower- le permiten solo mantener la fama. Agobiado por las deudas, el alcohol y problemas maritales, a finales de 1856 viaja a Europa, Roma, Grecia y el Medio Oriente. Melville fue un explorador ávido e incansable, ya sea en el mar, en tierra o navegando mentalmente desde su escritorio. Impregnado del arte clásico europeo ya de regreso en los Estados Unidos dedicó unos años a actuar como conferencista en el circuito de liceos dictando diversos temas como Estatuas de Roma (1857-58), Los Mares del Sur (1858-59) y Viajar (1859-60). Para Melville la idea es la de ser «joven y despreocupado, dotado de talento e imaginación» permitiendo que «el viaje también abra nuestro espíritu a los detalles», tal como lo describe en Viajar. Melville nos escribe relatos de viajes que a su parecer "no satisfacen el ansia: tan solo estimulan el deseo de ver".

Melville exploró el deseo de encontrar detalles y descansar de la vida urbana en los azares de alta mar por lo que en 1860 se embarcó en el Meteor, cuyo capitán era su hermano menor Thomas con la idea de circunnavegar el mundo. Por segunda vez atraviesa el Cabo de Hornos con recaladas en Chile y Perú para llegar a San Francisco cuatro meses después, a punto de embarcar a China, Melville es invadido por la nostalgia y regresa a la costa este vía el istmo de Panamá. El estallido de la Guerra de Secesión produce un estancamiento de la actividad literaria, Melville se enlista en el servicio civil y se muda con su familia a Manhattan luego de vender su casa en los Berkshires. En 1866 es nombrado inspector distrital de aduanas en la oficina de Nueva York con un salario de US\$ 4/día.

El año siguiente es trágico, supera una seria crisis matrimonial -a causa de su alcoholismo y mal carácter- evitando ser dejado por su esposa pero su hijo mayor Malcolm se suicida de un balazo. Melville tuvo la capacidad de aprender de la experiencia y decide involucrarse en la poesía. En 1876 publica su poemario Clarel. En 1885 se retira de la aduana, un año después su hijo Stanwix de 35 años muere de tuberculosis mientras que su hija Bessie de 32 años enfermó de artritis. 
En 1888 hace un viaje corto a Bermudas, a su retorno publica el poemario John Marr and other sailors, en 1891 Timoleon. Para entonces Melville acumulaba dolencias como una "gota reumática", problemas oculares y depresión. En 1891, a los 72 años muere de una aparente falla cardiaca, el certificado de defunción registró "una dilatación cardiaca, insuficiencia mitral y astenia". A su muerte dejó inéditos el poemario Weeds and Wildings, Chiefly: With a Rose or Two y el relato Billy Budd.

Melville fue un incansable viajero que tuvo el mar cerca de su vida, de sus emociones y de sus palabras. Esa capacidad de viajar lo llevó a puertos lejanos como Paita, que cobró tal importancia a mediados del siglo XIX con los balleneros británicos y norteamericanos, que fue uno de los pocos puntos de atraque de la flota ballenera en la costa sudamericana que contaba con una oficina del Consulado de los Estados Unidos. Llegaban centenares de embarcaciones, como lo hubiese hecho el Pequod del capitán Ahab y donde el mismo Melville pasó algunos días.

Es en Paita donde encontramos a nuestro segundo personaje. Miguel Grau Seminario (Piura, 27 de julio de 1834), su padre, Juan Manuel, un militar de Cartagena de Indias llegado con las tropas de Bolívar y su madre Luisa Seminario, perteneciente a una noble familia piurana. El matrimonio tuvo cuatro hijos entre 1831 y 1835, siendo Miguel María el tercero de ellos. Por entonces el Perú era una continua sucesión de guerras entre los caudillos de la independencia. Juan Manuel Grau se había retirado de la vida militar y se dedicaba al ejercicio de la Procuraduría y la representación de intereses de terceros ante el Estado. Luisa Seminario venía de un compromiso previo con Pío Díaz, un militar venezolano, que la abandonó con dos hijos. Juan Manuel Grau, acaso compensó el ímpetu militar abandonado con las conquistas amorosas, una de ellas fue con la joven Micaela Barrios con quien tuvo mellizos que nacieron en febrero de 1834, meses antes del nacimiento de Miguel. Debido a las continuas infidelidades de don Juan Manuel el matrimonio peligraba en 1835 tuvo otro hijo extramarital con Josefa Casariego-. En 1837 nacería José Dolores, hijo de Juan Manuel y Luisa, sin embargo las aventuras amorosas continuarían así como los hijos extramatrimoniales. En 1839 la dama Panchita Ordinola le daría un hijo a Juan Manuel mientras que Luisa se involucraría con un tal capitán Elisalde para quedar embarazada a mediados de ese año. El matrimonio Grau-Seminario terminaría por romperse definitivamente a fines de 1839 cuando Luisa entregó a Juan Manuel a sus tres hijos mayores: Enrique de ocho años, Dolores de seis y Miguel de cinco. En 1840 Pío Díaz decidió regresar a Piura a reencontrarse con Luisa Seminario con quien tuvo más hijos.

En 1842 Juan Manuel Grau se estableció en Paita donde fue nombrado vista de aduana. Paita era el segundo puerto importante del Perú, a medio camino de Panamá y muy cerca de las Galápagos - ruta tomada por los barcos que se dirigían al oriente-, una bahía perfecta en medio del arenal a lomo de mula del río Chira, saqueada por Lord Cochrane en 1819 y bautizada por el que fuera luego el Mariscal Miller como la "Jamaica de Sudamérica» por ser un gran depósito de contrabando. Paita era una zona de desembarco, de aprovisionamiento de víveres y de flete de la mercadería norteña (madera de algarrobo, algodón, tabaco, caña de azúcar, índigo, cochinilla) desde allí partían mulas con mercadería desembarcada en dirección a Lima. La corriente de Humboldt hacía más difícil la navegación hacia el Callao. Asimismo, Paita era un centro de intercambio postal recibiendo los barcos concesionarios del correo británico, francés y peruano. El señor 
Grau era el encargado de supervisar las labores de desembarco y embarque de mercadería mientras el personal sanitario se encargaba de la vigilancia de posibles enfermos dentro de la tripulación y si esto ocurría el barco se declaraba en cuarentena y no podía atracar en el puerto.

El señor Grau fue acompañado muchas veces por sus hijos varones en sus visitas al puerto, mientras su hija se quedaba en casa cuidada por su ama. Las continuas visitas al puerto familiarizaron a los niños con el mar y la rutina de las naves. Tiempo después, como era usual en la época, el niño Enrique se haría a la navegación a zonas cercanas como Guayaquil y Panamá. Por entonces un amigo de su padre, don Manuel Herrera -ciudadano panameño llegado a Piura con el avance de las tropas de Bolívar y que se dedicó al comercio marítimo entre Paita, Panamá y el Callao-, luego de algunos naufragios y negocios no rentables en el Chocó (provincia colombiana de la costa del Pacífico) retomó sus labores como navegante. La deserción de dos tripulantes de su bergantín dio la oportunidad al niño Miguel de 8 años 8 meses de ser embarcado en el bergantín Tescua en marzo de 1843, una embarcación de poca capacidad que a lo mucho albergaba una tripulación de ocho hombres, incluyendo al capitán. El niño Miguel fue entregado por su padre al capitán Herrera quien se encargaría de su educación naval, de este modo a lo largo de la travesía aprendería sobre el comportamiento del mar, el emplazamiento de las estrellas a ambos lados del Ecuador, el manejo de las velas y las amarras, el mantenimiento de la nave y de la firmeza necesaria para maniobrar el timón. ${ }^{(10)}{ }^{(11)}$ Estando la nave cerca de la isla

10 Thorndike G. Grau Los hijos de los libertadores. Fondo Editorial del Congreso. Lima 2006 pp 26-37.

11 Ortiz Sotelo J. Miguel Grau el hombre y el mar. Fondo Editorial del Congreso. Lima 2003, pp 39-46.
Gorgona en las costas de Colombia la nave naufragó, según algunas fuentes a causa de un temporal. Tanto Grau como Herrera fueron rescatados de la isla y volvieron a Paita en la Catalina donde por coincidencia trabajaba el niño Enrique Grau. Un año después ambos se embarcaron en la goleta Florita, nave en la continuaron con viajes a Panamá y por primera vez en la vida de Miguel, atracaron en el Callao. Era costumbre entonces que los barcos hagan paradas esporádicas en algunos puertos para tomar provisiones, desembarazarse de la tripulación incómoda, contratar nuevos operarios, gestionar el servicio postal y realizar actividades comerciales. Miguel Grau tenía diez años, permaneció tres meses en el Callao, viviendo en la goleta, mientras Herrera pernoctaba en un hotel, el niño absorbía toda la realidad de un puerto significativamente más grande y variado que Paita, con marineros de múltiples lenguas, cerca de un castillo fortificado y en medio de la incertidumbre política provocada por las luchas fratricidas entre caudillos republicanos. Aquel 10 de julio de 1844, la Florita levaría anclas en dirección a Paita.

Estando en Paita se tuvieron noticias de una epidemia de fiebre amarilla en Guayaquil, oportunidad que le sirvió al capitán Herrera para hacerse cargo de la conducción del bergantín Josefina, nave construida en Estados Unidos con una capacidad de 121 toneladas, allí volvió a embarcarse Miguel quien tuvo esporádicos encuentros con su padre. La Josefina realizó múltiples viajes comerciales de Paita hacia Panamá y el Callao, con algunas paradas en Huanchaco, llevaba carga, correo y pasajeros. En mayo de 1846 la poderosa Pacific Steam Navigation Company ingresaba a las aguas del mar del Sur con un barco recién construido, el Ecuador, la nueva tecnología hacía los viajes más rápido, con mayor capacidad de carga y hacía poco se había hecho la concesión del 
servicio postal europeo, el comercio de las naves a vela comenzaría su declive pero ya había entregado al niño Miguel Grau una significativa educación naval.

La experiencia naviera de permitió a Miguel Grau ser admitido como tripulante de un ballenero. El 29 de noviembre de 1846, durante el fondeado en Paita, a los 12 años de edad, un púber Miguel, se embarcó como ayudante en el ballenero Oregon (de 339 toneladas de capacidad) que había zarpado de Fairhaven el 12 de junio de 1845 bajo las órdenes del capitán Wimpenny. ${ }^{(12)}$ Curiosamente de aquel puerto partiría nuevamente el Acushnet el 18 de julio bajo las órdenes del capitán Rogers pero sin Melville a bordo. La tripulación estaba compuesta sobre todo de estadounidenses, además de seis marineros portugueses y dos canacas, habitantes de Oceanía. Grau pasará los siguientes 22 meses en una larga travesía que lo llevó hasta Kamchatka (Rusia), las entonces Islas Sandwich (hoy Hawaii) y las Islas Galápagos en busca de ballenas, siendo al parecer su función la de ayudar en las labores a bordo como la limpieza, el hervido de la carne de ballena o en la cocina. Miguel Grau se convierte a temprana edad en testigo de toda la actividad ballenera vivida por Melville y relatada en sus obras, incluyendo los motines, las tormentas, los accidentes y las experiencias con los tatuados marineros polinesios.

El Oregon regresó a Paita con escala en Tumbes el 27 de julio de 1847, con doscientos cuarenta barriles de espermaceti y setecientos sesenta de aceite, reiniciando el viaje dos semanas después para volver a las Galápagos, luego enrumbar hacia el sur al puerto de Talcahuano en Chile, la travesía no estuvo exenta de dificultades por el tiempo, el mar y los motines.

$12 \quad$ Starbuck A. Op. cit. pp, 424-5.
El Oregon retornó vía Tumbes a Paita el 17 de agosto de 1848 con mil ochocientos barriles de espermaceti y setecientos barriles de aceite de ballena, en esa oportunidad el joven Grau desembarca para quedarse. El Oregon retornó a su puerto de origen el 10 de marzo de 1849 . Pero más que lo cazado, veintidós meses de navegación ballenera habían forjado en Grau un sólido conocimiento del mar así como de las noblezas, dobleces y oscuridades de la naturaleza humana.

Meses después, a finales de 1849, Miguel Grau inició su carrera como marino mercante a bordo de la fragata nacional Peruana que zarpó del Callao. En esta etapa de su vida que se extiende hasta 1853 se embarcaría también en naves de bandera estadounidense e inglesa como la Conroy, Grace McVea, Couser, Witchcraft, Staghound, Seabon y Golden Eagle atracando en los puertos de Liverpool, Burdeos, Rio de Janeiro, San Francisco, Macao, Hong Kong, Shanghai, Singapur y las islas Sandwich. Por esos años se vivía la fiebre del oro en California y comenzó la inmigración china al Perú.

La personalidad de Grau se formaría férrea pero parca, rezagos de la dureza de la vida marina. Ya a finales de 1853, junto a su hermano y su padre, Juan Manuel Grau, se establecieron en Lima. Oportunidad para que el padre solicitara la inscripción de sus dos hijos al servicio naval del Perú, siendo aceptados como guardiamarinas el 14 de marzo de 1854, etapa que duraría hasta 1857. Miguel Grau volvería a la marina mercante durante el periodo 18591863 para retornar a su segunda etapa en el servicio naval de 1863 a 1867, periodo de la guerra con España y el combate naval de Abtao. Un incidente separaría a Grau y a otros oficiales de la Marina, su rebeldía a reconocer al estadounidense, el contralmirante John Randolph Tucker, como jefe de la escuadra peruana. Al salir trabajó por más de un año 
en la Pacific Steam Navigation Company donde llegó a ser comandante de buque, un cargo reservado en la compañía solo a oficiales británicos.

En 1868, ante la renuncia del presidente Prado, el nuevo jefe de Estado, el general Pedro Diez Canseco reincorporó a los oficiales del incidente Tucker. Miguel Grau lo hizo el 22 de enero y el 27 de febrero tomó el mando del monitor Huáscar que estuvo estacionado en Chile por dos años como parte de la Escuadra Aliada contra España. Con un pequeño intervalo en 1876, para desempeñarse como diputado por Piura, el monitor Huáscar y Grau formarían un binomio en el mar peruano, primero como vigía de nuestras costas y luego como héroes de la Guerra del Pacífico.

Grau, como Melville y el imaginario Ismael de Moby Dick, fueron tripulantes de un ballenero, testigos de los vigías oteando el horizonte en busca de su presa, la que al ser avistada era perseguida por los botes donde los arponeros intentaban dar en el blanco. Si la ballena era ensartada debían luchar contra la resistencia del animal hasta que desfalleciera. Con las mismas sogas, la ballena muerta era remolcada hacia el barco, donde era decapitada y luego trozada en pocas horas para evitar que los restos sobre el mar fueran comidos por los tiburones. La carne era hervida hasta obtener la sustancia grasa que luego se almacenaba en barriles. Durante las largas travesías del barco, una pequeña parte de la mercancía era intercambiada por comida y agua en los puertos del Pacifico.

Un barco ballenero se convertía no solo en un medio de producción sino en un micro mundo donde confluían hombres de distintas culturas y temperamentos, una reproducción a escala del mundo continental, con sus virtudes, coraje y miserias. Un tripulante solo tenía la certeza de que si bien se poseía una porción de la riqueza del ballenero, esta podría ser perdida completamente, a veces con la vida, en una epidemia, un motín, una tempestad o el furioso ataque de una ballena como contaba la leyenda del Essex que fue atacado por la venganza de un cachalote.

La tripulación de un ballenero consistía de un capitán, un primer oficial, que hacía de piloto y llevaba el cuaderno de bitácora; un segundo oficial, encargado del manejo del velamen y que en las naves comerciales se encargaba de la carga y descarga; un contramaestre que servía de enlace entre oficiales y marineros, un comisario, que se encargaba de los turnos; los empleados (carpintero, plomero, despensero, cocinero); los marineros se dividían en veteranos y bisoños. Las nacionalidades eran múltiples, daneses, holandeses, franceses, portugueses, españoles de las canarias, aborígenes de Oceanía y sudamericanos. ${ }^{(13)}$

Un marinero llevaba en su bolsa algunas mudas de ropa, cuchillo, pipa, tabaco de mascar, si era letrado llevaba consigo algunos libros (la mayoría de veces una biblia). La vida el marinero era incierta. Tal incertidumbre podría devenir en actuar como si la vida no importara al día siguiente o podría dar lugar a las más profundas reflexiones acerca del inconcluso significado de la vida y de la muerte, que es lo que se lee en Moby Dick.

La rutina del mar consistía en la limpieza del barco, el manejo de las velas. Recibían tres comidas al día (guiso de carne de cerdo con arroz o papas) una ración de galletas marineras y para beber café, té o chocolate. En los días de fiesta se mejoraba la ración o cuando se cruzaba la línea del Ecuador (punto donde se bautizaba

13 Pereira S. Op. cit. Cap. la Vida marinera norteamericana en el Pacífico pp. 261-273. 
a los bisoños rapándolos y sumergiéndolos en el estanque de agua).

Por lo general no existían médicos a bordo, el principal problema era el escorbuto, que generaba una hinchazón de las encías, sangrado y caída de dientes, razón por la cual los barcos se esmeraban por acercarse a los puertos para conseguir frutas frescas, así como barriles de agua. La presencia de epidemias a bordo podía diezmar la tripulación, como era el caso de la disentería. Las infestaciones con roedores eran comunes por eso debían realizar "humadas" antes de entrar a un puerto. Un número considerable de marineros contraía la sífilis, ya que al bajar al puerto contentaban la represión sexual con las prostitutas del lugar, en Paita el barrio rojo se llamaba Maintope, y no pocas veces aquellas mujeres se acercaban a los barcos en lanchas de vistosos colores para brindar sus servicios a bordo.
La vida del marinero, solitaria y áspera, generaba además espacio para las creencias y supersticiones, para las fantasías de seres extraordinarios o de ballenas asesinas como Mocha Dick ${ }^{(14)}$, para contemplar la inmensidad de la vida en la oscuridad del mar y el cielo estrellado, para forjar el carácter o echarse a perder. Miguel Grau, forjó su historia en el mar, al que nunca abandonó y fue su lecho de muerte. Herman Melville, tuvo una no pertenencia con la tierra que lo vio nacer, su voluntad aventurera nació en el mar y a pesar que navegó por pocos años, su obra literaria y arte poética fueron una reconstrucción de sus años marinos. Si Grau circuló vehementemente los océanos, Melville navegó en el mar de las palabras hasta el final de sus días.

CORRESPONDENCIA: aldo.vivar@upch.pe

14 Mocha Dick era el nombre de una legendaria ballena asesina muy extendida entre los marineros de la época. 